\author{
E H El-Mossalamy*¹ ${ }^{1}$,Waleed E. Mahmoud ${ }^{2,3}$,M. Hafez ${ }^{3}$ \\ ${ }^{1}$ Chemistry Department- Faculty of Science- King AbdulAziz University- P.O.Box.80203- \\ Jeddah 21589 - Saudi Arabia; \\ ${ }^{1}$ Chemistry Department-Faculty of Science- Benha University- Benha- Egypt \\ ${ }^{2}$ Physics Department- Faculty of Science- King AbdulAziz University- \\ ${ }^{3}$ Physics Department-Faculty of Science- Suez Canal University, Ismaillia- Egypt
}

\title{
THE EFFECT OF NANOSCALE BISMUTH OXIDE ON THE ELECTRICAL AND MECHANICAL PROPERTIES OF POLYVINYL ACETATE
}

\begin{abstract}
Polyvinyl acetate (PVAc) loaded $\mathrm{Bi}_{2} \mathrm{O}_{3}$ nano-particles were successfully prepared at room temperature and ambient pressure. Transmission electron microscopy was used to characterize the final product. It was found that $\mathrm{Bi}_{2} \mathrm{O}_{3}$ nanoparticles were well dispersed and uniform in shape and the diameter of the particles was confined within $8 \mathrm{~nm}$. Addition of small amounts $(0.2-1 \mathrm{wt} \%)$ of nano-scales Bismuth oxide $\left(\mathrm{Bi}_{2} \mathrm{O}_{3}\right)$ to polyvinyl acetate (PVAc) are increased the electrical conductivity as well as the modulus of elasticity. The deformation behavior after yielding of the nanocomposites, irrespective of $\mathrm{Bi}_{2} \mathrm{O}_{3}$ concentration is similar to the unfilled elastomer, implying that the mechanism of large deformation is mainly governed by the matrix.
\end{abstract}

\section{INTRODUCTION}

Heavy metal oxide based polymers have attracted a great deal of attention in recent years [1-4]; these studies have yielded valuable information regarding the structural transformations that are taking place in these polymers. The polymers containing bismuth ions have attracted our interest in expect of their potential applications in memory and switching devices $[5,6]$.

Recently, bismuth oxide $\left(\mathrm{Bi}_{2} \mathrm{O}_{3}\right)$ has been investigated extensively due to its optical and electrical properties such as refractive index, large energy band gap, dielectric permittivity as well as remarkable photoluminescence and photoconductivity. These properties make bismuth oxide an interesting candidate for applications in the fields such as optoelectronics, optical coatings, gas sensors, Schottky barrier solar cells, metal-insulatorsemiconductor capacitors, microwave integrated circuits, etc. $\mathrm{Bi}_{2} \mathrm{O}_{3}$ shows four main structures that are denoted by $\alpha-, \beta-, \gamma-$, and $\delta-\mathrm{Bi}_{2} \mathrm{O}_{3}$ [7]. The low-temperature $\alpha$-phase and high-temperature $\delta$-phase are stable, and the others are high-temperature metastable phases 
[8]. These special features explain the great effort devoted to the investigation of $\mathrm{Bi}_{2} \mathrm{O}_{3}$ polymorphs over the last years.

Since no experimental work has been reported about the effect of bisthmus oxide on the polymeric materials, the future application of these materials strongly depends on the success of improving their mechanical and electrical properties. With this scope, the aim of the present contribution is to present a new data for the effect of $\mathrm{Bi}_{2} \mathrm{O}_{3}$ on the electrical and mechanical properties of PVAc in details as much as possible.

\section{EXPERIMENTAL}

\section{Materials and processing}

Films from PVAc (M.W. 34,000) filled with different amounts $(0,0.2,0.4,0.6,0.8$ and $1 \mathrm{wt} \%$ ) of nano-scale bisthmus oxide (density $=6 \mathrm{~g} / \mathrm{cm}^{3}$, particle size $=8 \mathrm{~nm}$ ) were prepared by casting method as follows. Polymer solution was prepared by adding $6 \mathrm{~g}$ PVAc into $100 \mathrm{ml}$ deionized water and stirring at $90^{\circ} \mathrm{C}$ until a viscous transparent solution was obtained. Bisthmus oxide was dissolved in deionized water also and added to the polymeric solution. These solutions were left to reach a suitable viscosity, after that they were cast in glass dishes and left to dry in a dry atmosphere at room temperature. Samples were transferred to an electric oven held at $60^{\circ} \mathrm{c}$ for $48 \mathrm{~h}$ to minimize the residual solvent. The thickness of the obtained films was in the range 0.1 to $0.2 \mathrm{~mm}$. Figure 1 depicts the TEM micrograph of the as-prepared PVAc loaded $0.2 \mathrm{wt} \%$ of $\mathrm{Bi}_{2} \mathrm{O}_{3}$ nanocrystals. The spherical particles were well dispersed in PVAc matrix with a diameter of $(8.3 \pm 1.6 \mathrm{~nm})$. For the rest samples $(0.4,0.6,0.8$ and $1 \mathrm{wt} \%)$ the average particle size was increased due to the tendency of nano filler to agglomerate and it was found $9.4 \pm 0.5 \mathrm{~nm}, 31.2 \pm 1.4 \mathrm{~nm}$, $54.2 \pm 1.3 \mathrm{~nm}$ and $73.1 \pm 2.5 \mathrm{~nm}$ respectively.

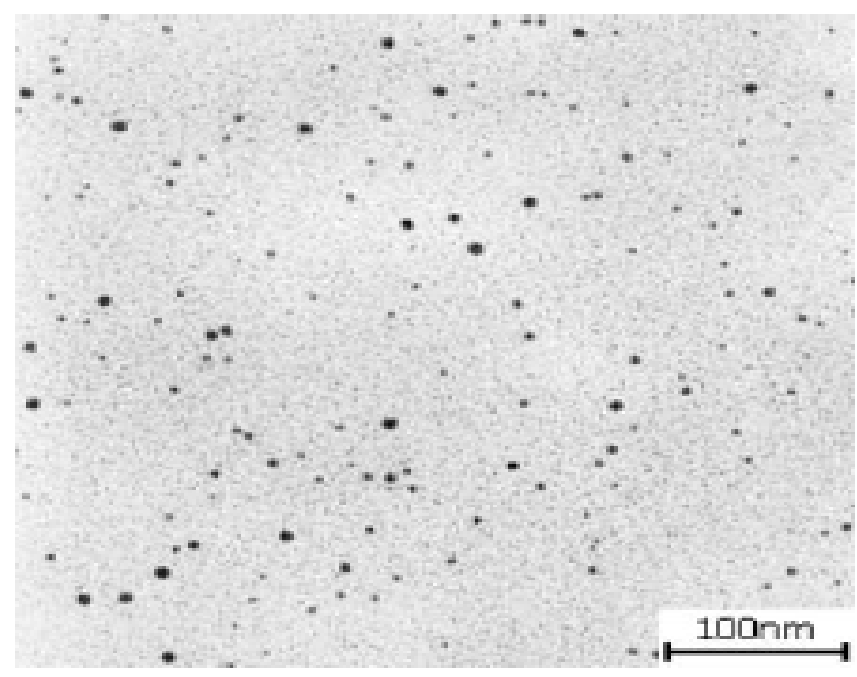

Fig. 1. TEM micrographs of PVAc-loaded $0.2 \mathrm{wt} \%$ of $\mathrm{Bi}_{2} \mathrm{O}_{3}$ nanoparticles 


\section{Measurements}

The stress-strain behavior in case of uniaxial extension was measured at room temperature by using a material tester (AMETEK, USA), which connected by a digital force gage (Hunter Spring ACCU Force II, 0.01 N resolutions, USA) to measure the stress force. The force gage interfaced with computer to record the obtained data. The stressstrain behavior was measured at strain rate $0.1 \mathrm{~mm} / \mathrm{s}$. For electrical measurements a digital electrometer (616 Keithly, USA) was used to measure the current.

\section{RESULTS AND DISCUSSION}

\section{Electrical Conductivity}

The dependency of electrical conductivity of $\mathrm{Bi}_{2} \mathrm{O}_{3} / \mathrm{PVAc}$ nanocomposites on the filler content is shown in Fig. 2. It is shown that around $0.5 \mathrm{wt} \%$ of the filler, sharp increase of electrical conductivity was observed. This concentration is generally called percolation concentration. In this case infinite cluster of particles is formed within the polymeric matrix. This cluster penetrates throughout the sample and represents a conductive way for movement of electrons throughout the sample. From this concentration of the filler the material dramatically changes its electrical conductivity and becomes conductive. Since in a real situation only limited number of experimental points is available, we arbitrary identified a percolation threshold as an inflexion point in an empirical fitting curve. For a fitting of experimental data Eq. (1) [9-10] was suggested.

$$
\log \left(\frac{\sigma_{c}}{\sigma_{m}}\right)=B\left(1-e_{f}^{-a \phi}\right)^{n}
$$

where $\mathrm{B}, \mathrm{a}$ and $\mathrm{n}$ are adjustable parameters, $\sigma_{\mathrm{c}}$ is the electrical conductivity of composites, $\sigma_{\mathrm{m}}$ is the electrical conductivity of polymeric matrix and $\phi_{\mathrm{f}}$ is the volume fraction of filler. An inflexion point $\phi_{\mathrm{i}}$ of this dependence, which was identified with percolation concentration $\mathrm{fc}$ is calculated according to Eq. (2).

$$
\phi_{i}=\phi_{c}=\frac{\ln (n)}{a}
$$

It was found that the parameter B can be approximately expressed as

$$
B=\log \left(\frac{\sigma_{c, \text { max }}}{\sigma_{m}}\right)
$$

where $\sigma_{c, \text { max }}$ is a value of electrical conductivity of composites at maximum experimentally used concentration of the filler. The parameters $\mathrm{B}$, a and $\mathrm{n}$ are 12.2, 23.4 and 10.7 respectively. 


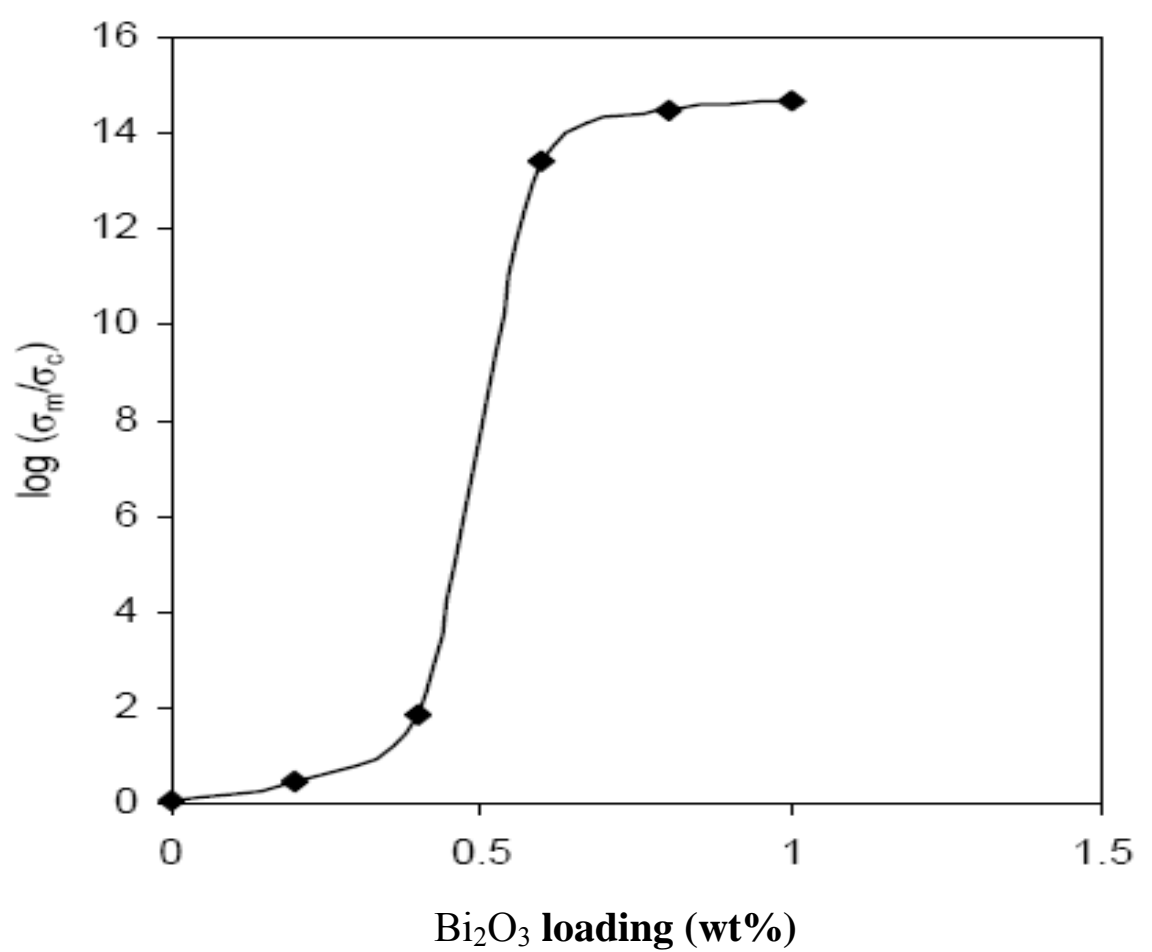

Fig. 2. The log of relative conductivity as a function of filler loadings

\section{Mechanical properties}

Figure 3 shows the stress-strain curves obtained at different amounts of $\mathrm{Bi}_{2} \mathrm{O}_{3}$ dispersed in the PVAc matrix. It was found that by increasing the concentration of filler, gradual improvement in modulus was observed. The results were compared with Guth reinforcement model [11]. The model for spherical reinforcing particles has the form:

$$
\mathrm{E}=\mathrm{E}_{\mathrm{o}}\left(1+2.5 \mathrm{C}+14.1 \mathrm{C}^{2}\right)
$$

where $E$ and $E_{\mathrm{o}}$ are the moduli of the filled and unfilled matrix, respectively and $\mathrm{C}$ is the filler weight fraction. The linear term in Eq. (4) accounts for the reinforcing effect of individual particles, and the second power term is the contribution of particle pair interactions. This model fits well the experimental data, as shown in Fig. 4.

Figures $5 \mathrm{a}$ and $5 \mathrm{~b}$ summarize the engineering stress $\left(\sigma_{\mathrm{Y}}\right)$ and strain $\left(\varepsilon_{\mathrm{y}}\right)$ at the apparent yield point; engineering stress $\left(\sigma_{b}\right)$ and strain $\left(\varepsilon_{b}\right)$ at rupture. These figures indicate that, the engineering stress at the apparent yield point increases roughly monotonically with $\mathrm{Bi}_{2} \mathrm{O}_{3}$ loading and the elongation at the apparent yield decreases precipitously between 0 and $0.6 \mathrm{wt} \%$ of $\mathrm{Bi}_{2} \mathrm{O}_{3}$ and is approximately invariant at higher loadings. Although this transition occurs at loadings greater than electrical percolation, this behavior may reflect the failure of reinforcing network of $\mathrm{Bi}_{2} \mathrm{O}_{3}$ and polymer crystallites, which occurs at higher loadings. This loading of $\mathrm{Bi}_{2} \mathrm{O}_{3}$ also corresponds approximately to a rapid increase in the initial soft segment crystallinity. Finally, the elongation at rupture decreases slightly with $\mathrm{Bi}_{2} \mathrm{O}_{3}$ loading; however even at $1 \mathrm{wt} \%$ of $\mathrm{Bi}_{2} \mathrm{O}_{3}$, still results in a thermoplastic elastomer with $150 \%$ elongation before failure. 


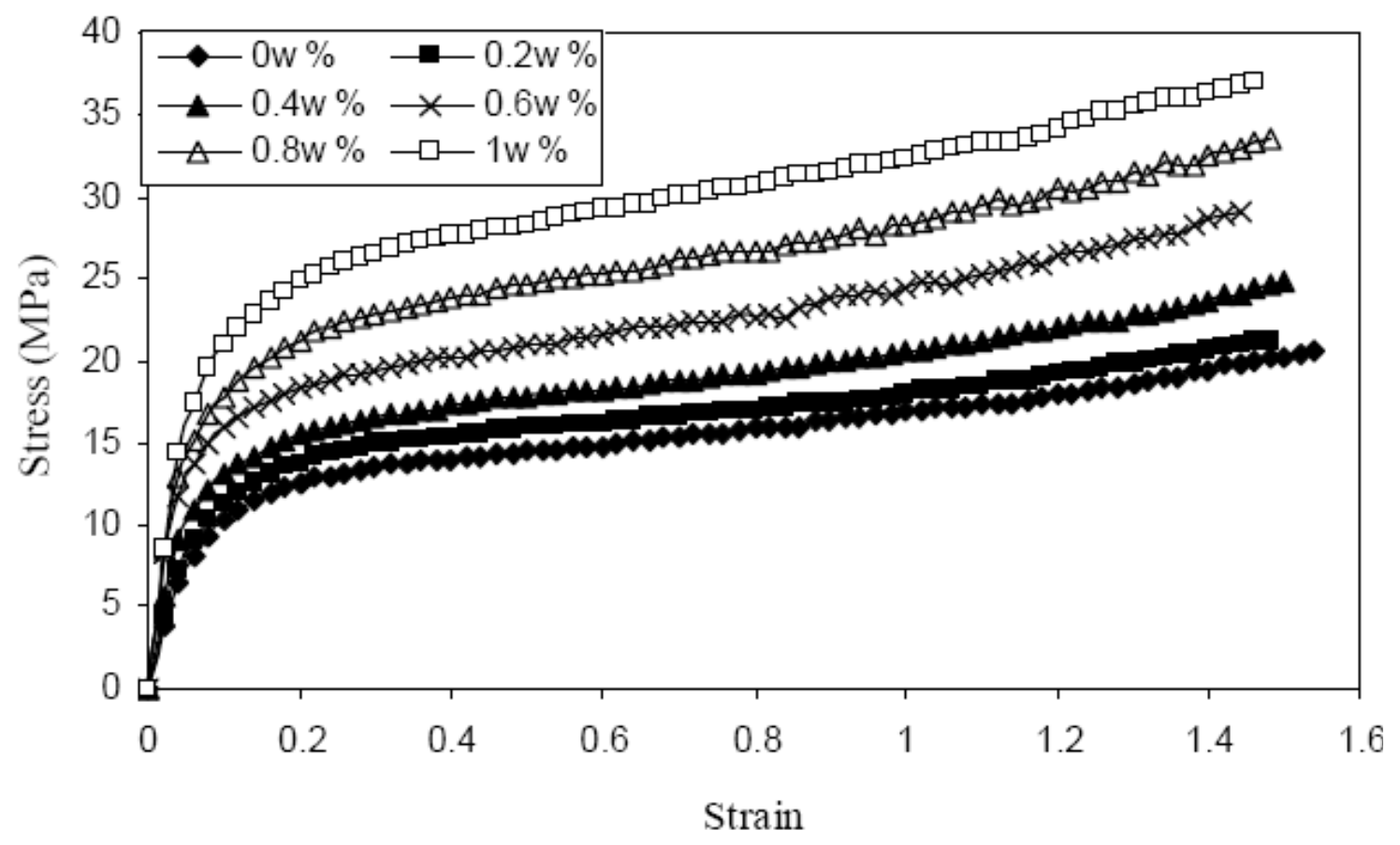

Fig. 3. stress-strain curves for prepared samples

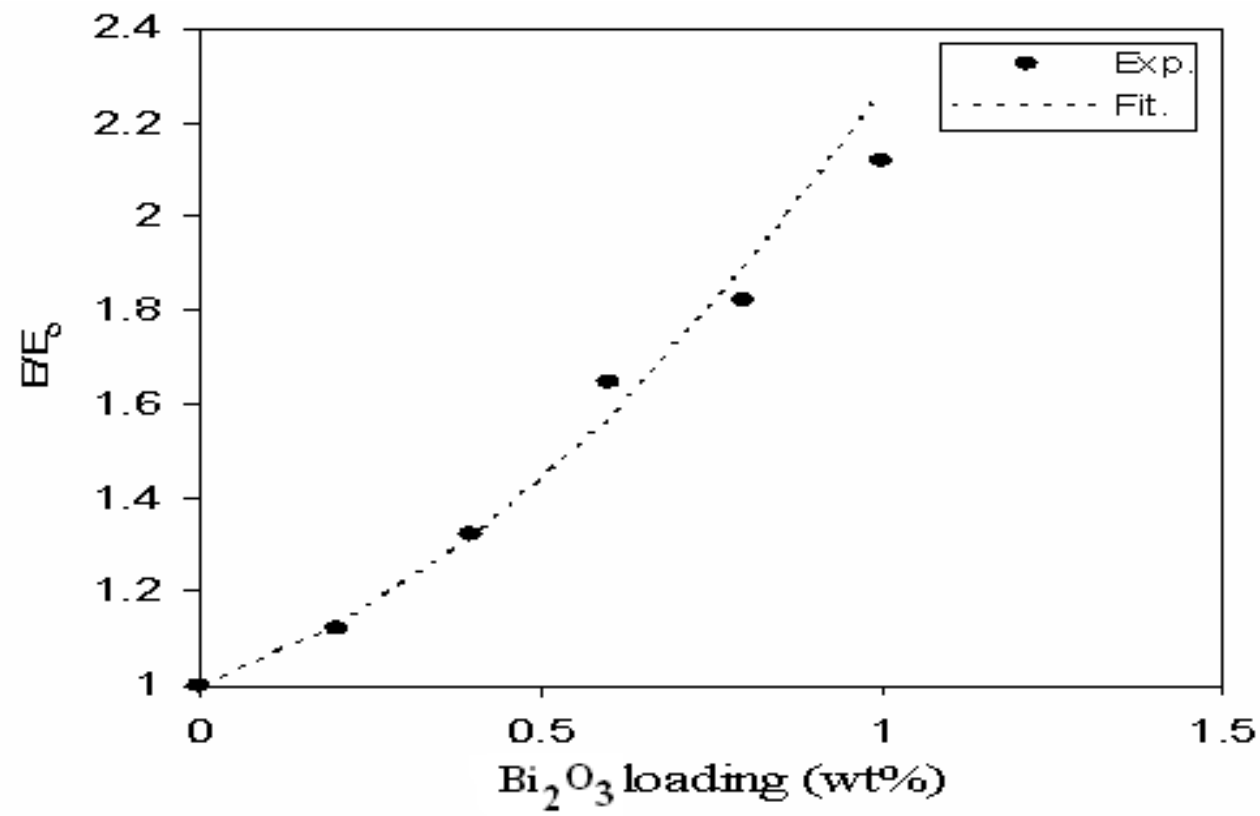

Fig. 4. A comparison between experimental and fitted relative modulus as a function of filler loading ( $w t \%)$ 
a)

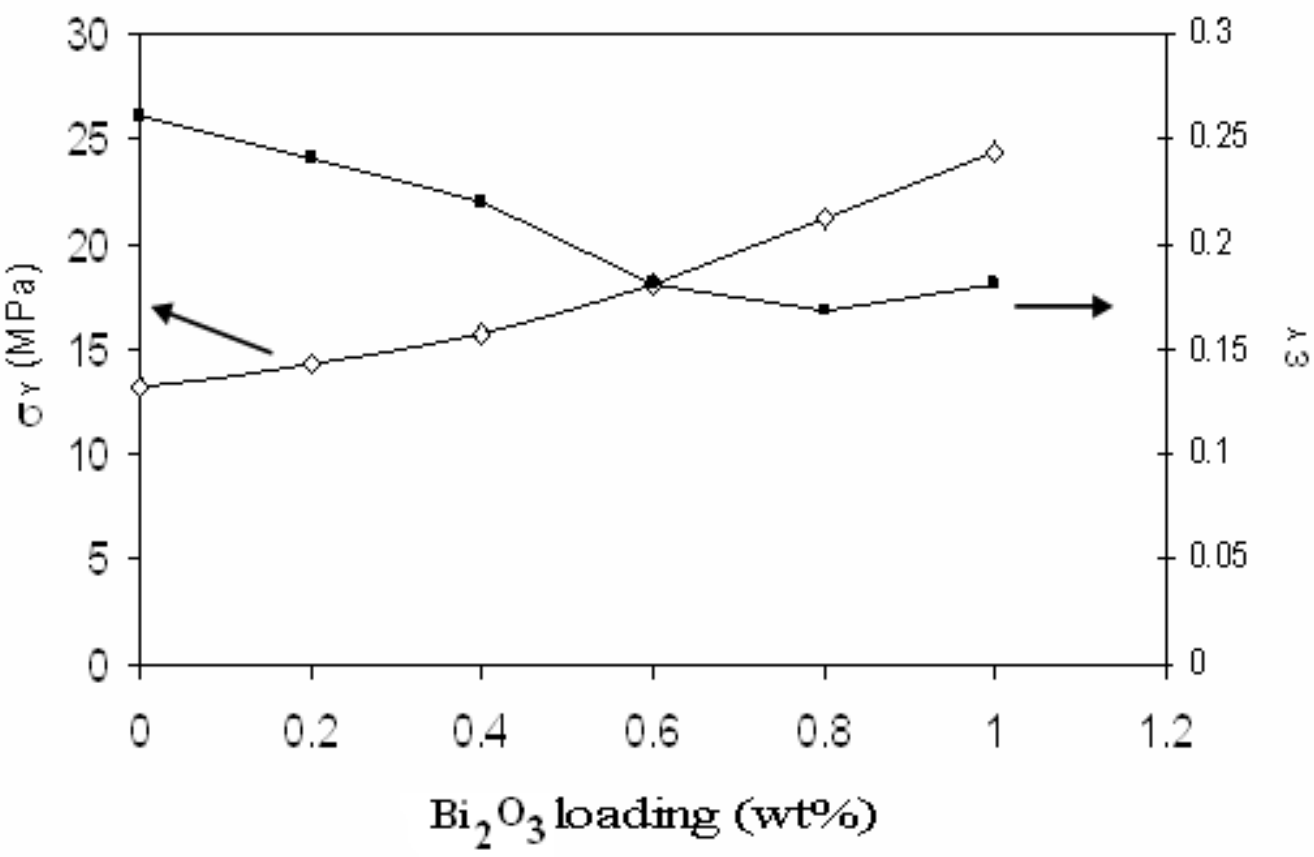

b)

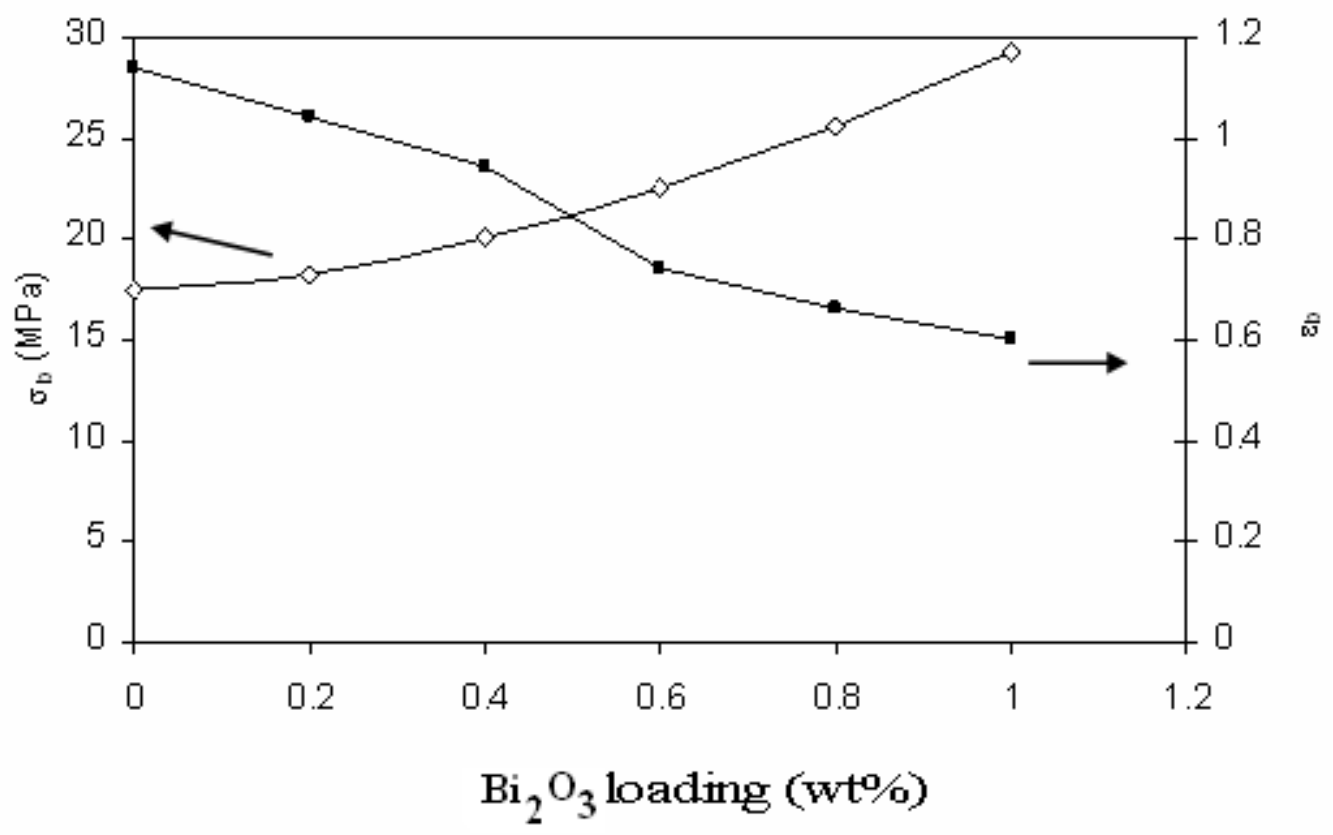

Fig. 5. The deduced mechanical parameters 


\section{Mooney-Rivlin Equation}

The framework to understand rubber elasticity at small deformations was established elsewhere [12]. The 'affine' deformation (components of vector length or endto-end distance of each chain is changed in the same ratio as the corresponding dimensions of the bulk rubber) of a network of Gaussian chains can be equivalently understood from the perspective of thermodynamic elasticity or strain invariants, such as storable elastic energy [11]. Starting from this foundation, the impact of various complexities, such as filler content, cross-link fluctuation, non-affine deformation (Phantom network theory [13]), distribution in cross-link functionality, chain constraints and free chains, can be discussed. To establish a connection to these previous efforts and begin to quantitatively understand the unique impact of nanoscale, high aspect fillers, on thermoplastic elastomers, it is instructive to compare the experimental data to these existing frameworks. The strain invariant approach of Mooney-Rivlin, extensively utilized for filled rubbers, provides a straightforward approach to examine the deviation of a complex elastomeric system from ideality. The stress ( $\sigma$, here the engineering stress)-elongation ratio $(\lambda)$ relationship is expressed as:

$$
\sigma=2\left(C_{1}-\frac{C_{2}}{\lambda}\right)\left(\lambda-\lambda^{-2}\right)
$$

where $\lambda=\left(L / L_{o}\right)+1$, and $C_{1}$ and $C_{2}$ are constants reflecting characteristics of the network. $C_{2}$ represents the non-Gaussian aspects of the network, such as physically (unstable) crosslinks. When $\mathrm{C}_{2}=0,2 \mathrm{C}_{1}=\mathrm{G}$, the shear modulus and Eq. (5) reduces to the well-known expression for deformation of a Gaussian network [12]. Figure 6 depicts the effective modulus $\left(\sigma / 2\left(\lambda-\lambda^{-2}\right)\right)$ of the BI2O3/PVAC with respect to the inverse elongation ratio, $\lambda^{-1}$. Affine deformation of an ideal Gaussian network $\left(\mathrm{C}_{2}=0\right)$ would appear as a horizontal line. The pure thermoplastic elastomer exhibits substantial non-ideality during deformation, attributed to meta-stability of physical crosslinks, complex morphology of hard-segment crystallites and strain-induced crystallization of soft-segments. As the $\mathrm{Bi}_{2} \mathrm{O}_{3}$ loading increases the non-ideal behavior increases, especially at low deformation. After yield, the relative behavior of the nano composites is similar, irrespective of $\mathrm{Bi}_{2} \mathrm{O}_{3}$ loading. Figure 7 emphasizes the similarity between all the systems above yielding; implying that the mechanistic of deformation beyond the yield point is dominated by the elastomer, with minimal impact from the $\mathrm{Bi}_{2} \mathrm{O}_{3}$ s. Also notable in Figure 7 is the appearance of a threshold volume fraction at which all nano composites behave identical over the entire deformation range. In addition to $\mathrm{Bi}_{2} \mathrm{O}_{3}$ loading, the initial soft segment crystallite content also changes between 0 and $0.6 \mathrm{wt} \% \mathrm{Bi}_{2} \mathrm{O}_{3}$ and may contribute to this behavior. Overall, one concludes that the addition of $\mathrm{Bi}_{2} \mathrm{O}_{3}$ to $\mathrm{PVA}_{\mathrm{C}}$ increases the modulus and strength of $\mathrm{PVA}_{\mathrm{C}}$ without sacrificing deformability. 


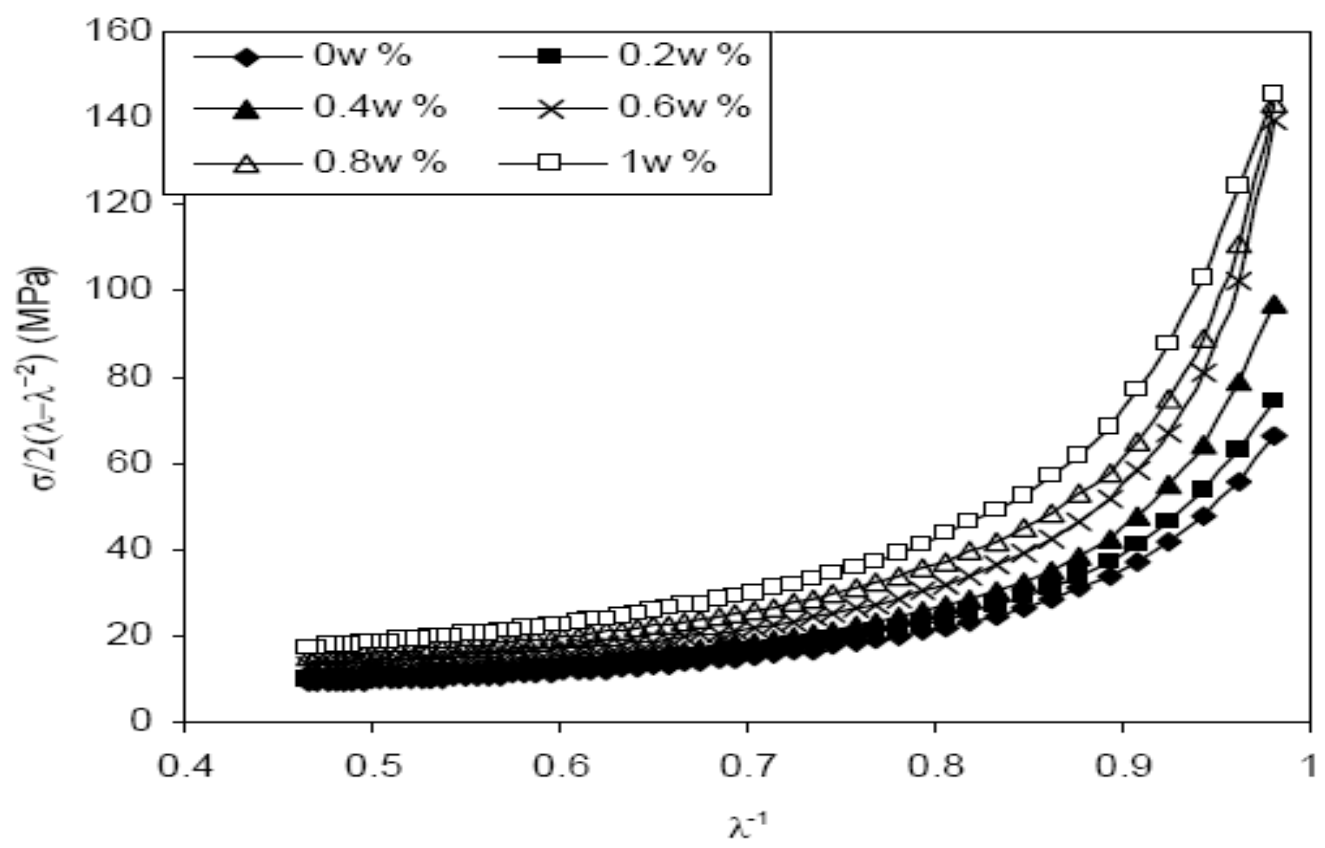

Fig. 6. plot of Mooney-Rivlin relationship for all prepared samples

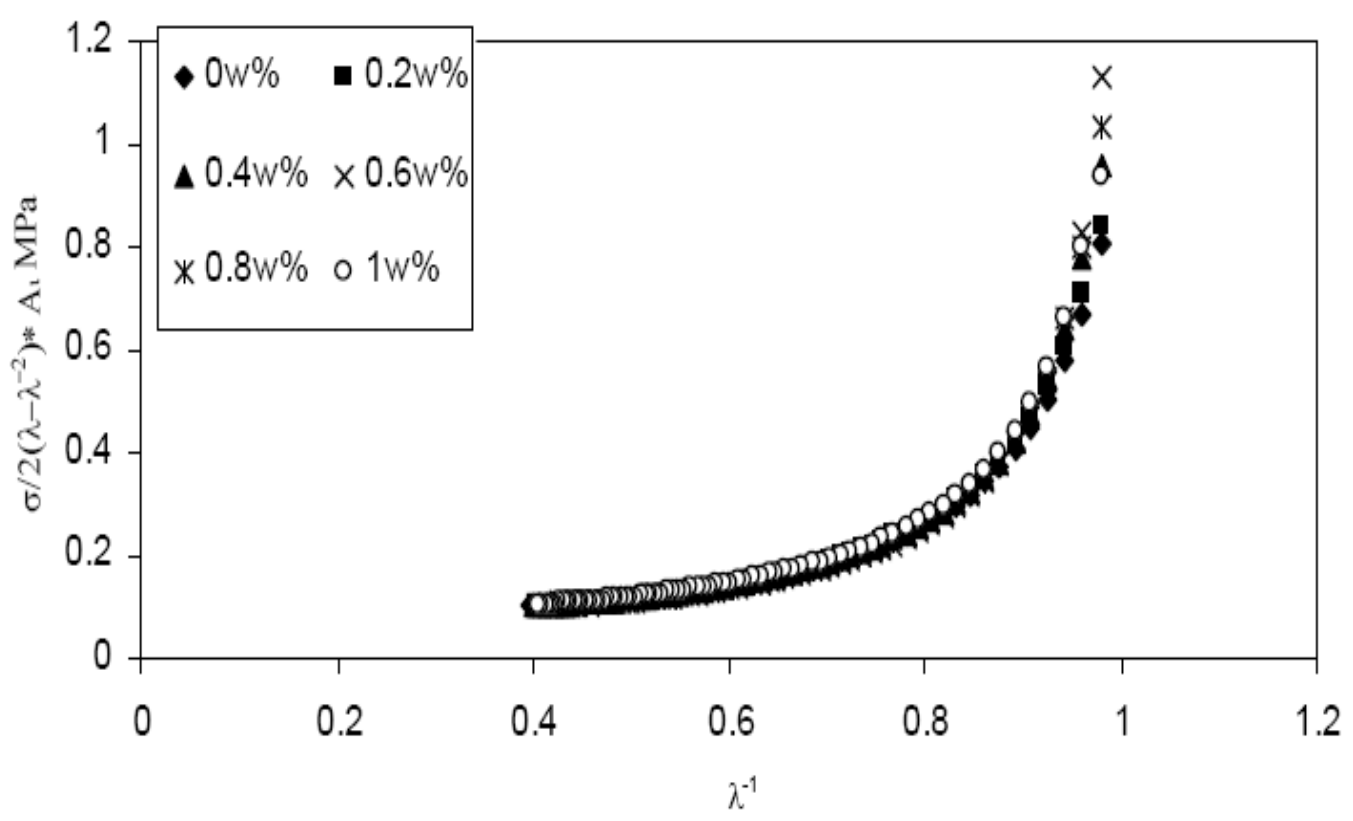

Fig. 7. plot of Mooney-Rivlin relationship for all prepared samples multiplied into the shift factor $\mathrm{Ai}$ 


\section{CONCLUSION}

Polyvinyl acetate loaded different concentrations of bisthmus oxide nanoparticles were prepared. The particle size was determined from transmission electron microscope and it is about $8.3 \mathrm{~nm}$. A small addition of $\mathrm{Bi}_{2} \mathrm{O}_{3}$ nanoparticles to the PVAc matrix increased the electrical conductivity. The percolation concentration was around $0.5 \mathrm{wt} \%$. Also the addition of $\mathrm{Bi}_{2} \mathrm{O}_{3}$ nanoparticles increased the strength of PVAc without loss of the ability to stretch the elastomer above $150 \%$ before rupture. The deformation behavior after yielding was the same for filled and unfilled polymer, implying that the mechanism of large deformation is mainly governed by the matrix.

\section{REFERENCES}

1. Waleed E Mahmoud and H M El-Mallah, Physics D: Applied Physics 42 (2009) 035502 .

2. Waleed E Mahmoud, M Hafez, N A El-Aal and F El-Tantawy, Polymer International 57 (2008) 35.

3. P K Khanna, N Singh, S Charan, A K Viswanath, K R Patil, Material Research Bulletin 42 (2007) 1414.

4. N B Pendyala, K S R Koteswara Rao, Luminescence 128 (2008) 826.

5. Novak I, Krupa I and Chodak I, Synthetic Metals, 131 (2002) 93.

6. Novak I, Krupa I and Chodak I, European Polymer, 39 (2003) 585.

7. Shuk, P.; Wiemhöfer, H.-D.; Guth, U.; Göpel, W.; Greenblatt, M. Solid State Ionics, 89 (1996) 179.

8. Leontie, L.; Caraman, M.; Visinoiu, A.; Rusu, G. I. Thin Solid Films, 473 (2005) 230 .

9. Novak I., Krupa I. and Chodak I., Synthetic Metals, 131 (2002) 93.

10. Novak I., Krupa I. and Chodak I., European Polymer, 39 (2003) 585.

11. Mahmoud W. E., El-Eraki M. H. I., El- Lawindy A. M. Y. and Hassan H. H., Physics D: Applied Physics, 39 (2006) 541.

12. El-Eraki M. H. I., El- Lawindy A. M. Y., Hassan H. H. and Mahmoud W. E., Polymer Degradation and Stability, 91 (2006)1417.

13. Farago O. and Kantor Y., European physics Letters, 52 (2000) 413. 